\title{
Padrões físicos inadequados na performance musical de estudantes de violino
}

\author{
Carolina Valverde Alves (UEMG, Belo Horizonte, MG) \\ carolina.valverde@gmail.com.br
}

\begin{abstract}
Resumo: 0 presente artigo, uma exposição resumida da dissertação de mestrado (2008), discute a observação e avaliação dos problemas corporais que permeiam a prática de seis estudantes de violino do curso de Graduação da Escola de Música da UFMG. Dados foram colhidos através de observação, filmes e fotos de seis alunos de violino em quatro situações diferentes de performance no contexto do curso, além de avaliações fisioterápicas realizadas no consultório de Fisioterapia da pesquisadora. Estes dados foram apresentados a um painel composto por quatro observadores da área da saúde e da música. A análise destes dados revela que os seis alunos de violino apresentaram padrões fisicos inadequados que poderiam prejudicar sua saúde e, consequentemente, sua performance. Além disso, foi conduzida uma pesquisa bibliográfica envolvendo estudos relacionados à Anatomia, Biomecânica e Cinesiologia. Esperamos que este artigo possa chamar a atenção dos violinistas e professores de violino para a importância de uma consciência corporal durante a performance do instrumento, que vise mais simetria e relaxamento das regiões corporais envolvidas no ato de tocar o violino.
\end{abstract}

Palavras-chave: saúde do músico; lesões físicas em violinistas; estudantes de violino.

\section{Inadequate physical patterns in musical performance of violin students}

Abstract: This article, a summary of the Master thesis (2008), discusses the observation and evaluation of physical problems presented by six Bachelors students of the Music School of UFMG (Brazil), in their violin practice. Data was collected through observation, films and photos of six violin students at four different situations of performance in the context of their program, besides the physiotherapeutic assessments held in the office of the physiotherapist researcher. This data was then submitted to a panel composed of four observers, health and music specialists. The analysis of this data reveals that the six violin students showed inappropriate physical patterns that could jeopardize their performance as well as their health. Also, a bibliographic survey related to the Anatomy, Biomechanical and Kinesiology was conducted. It is hoped that this research draws the attention of violinists and violin teachers to the importance of body consciousness whilst performing the instrument, emphasizing the need to maintain the symmetry and body relaxation of those parts involved in the act of playing the violin.

Keywords: musician's health; physical injuries in violin players; violin students.

\section{Introdução}

0 presente artigo foi elaborado a partir do estudo intitulado "Padrões físicos inadequados em estudantes de violino na performance musical", de natureza qualitativa, que foi realizado nas dependências da Escola de Música da UFMG e no Consultório de Fisioterapia da pesquisadora, na cidade de Belo Horizonte, Minas Gerais, durante 0 ano de 2007. ${ }^{1} 0$ interesse da pesquisa se dirigiu à observação da prática instrumental de seis alunos de violino do curso de graduação e envolve as seguintes áreas relacionadas à Fisioterapia: Anatomia, que é o estudo das estruturas do corpo humano; Biomecânica, que é o estudo da estrutura e da função dos sistemas biológicos utilizando métodos da mecânica; e Cinesiologia, que é o estudo do movimento humano.
Nos últimos 20 anos, instrumentistas têm voltado seus olhares para a consciência do uso corporal durante a performance musical. Profissionais da área de saúde, principalmente os da reabilitação física, têm se deparado com grande número de pacientes músicos em seus consultórios. Trata-se de uma realidade mais frequente do que se imagina, fazendo-se necessário um aprofundamento nos estudos relacionados à saúde física do músico. Nota-se, então, uma crescente preocupação de alguns autores quanto ao assunto, que toma enormes proporções, sendo explorado tanto em outros paises quanto no Brasil (BRODSKY e HUI, 2004; ZAZA, 1998; VISENTING e SHAN, 2003; BRANDFONBRENER e BURKHOLDER 2004; LAGE, et al., 2002; RICHERME, 
1996; SANTIAGO, 2000; 2004; 2005; 2006; FONSECA, 2005; PEDERIVA, 2005; 2006; LIMA, 2007; ANDRADE e FONSECA, 2000).

A partir de extensa busca de pesquisas na área da saúde do músico, observamos a existência de uma variedade de termos para designar os problemas corporais experimentados pelos músicos devido à prática musical. Com o objetivo de facilitar a escrita e a compreensão deste texto, devido aos vários termos encontrados na literatura para designar os tipos de lesões físicas sofridas pelos músicos por causa do mau uso do corpo em suas atividade musicais, decidimos utilizar a sigla DMRP- doença musculoesquelética ${ }^{2}$ relacionada à performance em todos os momentos que nos referirmos a esta problemática.

Pesquisadores demonstram uma preocupação com a necessidade de se formar um sistema de intervenção precoce para o tratamento das DMRP's. Conforme MILANESE (2000, p.107), "músicos profissionais têm sido identificados como um grupo ocupacional com um risco significativo de adquirirem DMRP's ao trabalho, devido às suas demandas ocupacionais". Essa ideia endossa nossa preocupação de incentivar ações no sentido da prevenção e principalmente da promoção da saúde do músico ao invés de trabalhar apenas com a reabilitação individual dos mesmos através do tratamento fisioterápico. Para este fim, temos participado de encontros e seminários com objetivo educativo.

Principalmente nos últimos seis anos, temos nos deparado, através de pesquisa e atendimento (EXERSER-Núcleo de Atenção Integral à Saúde do Músico) com grande número de violinistas buscando tratamento para seus problemas físicos. Na maioria das vezes, eles apresentam queixas graves e têm sido muitas vezes impedidos de realizarem suas atividades musicais. Podemos citar algumas queixas, dentre outras: "ombro congelado" (perda ou diminuição dos movimentos do ombro); epicondilite (dor no cotovelo); hérnia de disco (acontece quando o disco intervertebral, que é a cartilagem entre as vértebras, sai de seus limites fisiológicos); torcicolo; problemas nas ATM's (articulações têmporo-mandibulares que são as articulações da mandíbula, responsáveis pela abertura e fechamento da boca); dor de cabeça e dormência. Essas queixas coincidem com as descritas em artigos e dissertações sobre saúde do músico, especialmente do violinista (SHAN, VISENTIN e SCHULTZ, 2004; GREEF, WIJCK, et al., 2003; ANDRADE e FONSECA, 2000; DAWSON, 2001).

Há um visivel despreparo dos profissionais da área de saúde no trato com pacientes músicos (FRANK e MUHLEN, 2006, p.1; ROSET-LLOBET et al., 2000, p.167174; FONSECA, 2007, p.2). DAWSON (1998) afirma que encontrar um profissional da saúde que entenda dos problemas físicos do músico é um desafio, por existirem poucos que possuem o conhecimento e habilidade para tratar desta questão tão específica. "Poucos deles falam a linguagem do músico e ao mesmo tempo poucos músicos conhecem os jargões médicos ou sabem algo sobre a função e a estrutura do corpo" (DAWSON, 1998, p.4550). No entanto, não existem cursos de especialização oficializados em Fisioterapia que motivem a realização de investigações sérias na área da Saúde do Músico. Segundo GREEF (2003, p.156-160), "[...] as terapias clássicas que estão focalizadas somente no relaxamento, na medicação, na Fisioterapia tradicional e na cirurgia têm se mostrado inadequadas na solução dos problemas das DMRP's".

Da mesma forma, há uma falta de informação e orientação por parte dos músicos quanto à importância de maior consciência relativa ao funcionamento básico de seu corpo durante a performance. Normalmente, nas escolas de música, não é dada ênfase ao conhecimento da demanda de trabalho das estruturas do corpo envolvidas no ato de tocar um instrumento musical e os possíveis problemas físicos que poderão dificultar a atuação do músico instrumentista (MOURA et al., 2000, p.103-107). Sendo que não se tem notícia de que existam escolas de música no Brasil que incluam, em seu currículo básico da graduação, disciplinas relacionadas com o conhecimento de Anatomia e Fisiologia Humana e suas implicações para a prática com o instrumento. Adicionalmente, não há uma consciência por parte da maioria dos músicos quanto à importância de se consultar profissionais da área da saúde, quando surgem sintomas de problemas físicos devido ao estudo e performance instrumento (LLOBET et al., 2000, p.167-174).

Além dos detalhes anatômicos e técnicos do violino - conforme MC CULLOUGH (1996, p.2), a estrutura física do violino e a maneira de tocá-lo demandam dos instrumentistas um posicionamento assimétrico geral (diferença de posicionamento das regiões nos dois lados do corpo), como podemos constatar no Ex.1 - um dos motivos que levou à escolha do violinista como objeto deste estudo foi o grande número de trabalhos publicados sobre a situação da saúde deste instrumentista (por exemplo, KANEKO, LIANZA e DAWSON, 2005; SHAN et al., 2004; CARRINGTON e CAREY, 1992; BOWIE, BRIMER et al., 2000: CNIRVEC, 2004, COSTA e ABRAHÃO, 2004).

0 motivo pelo qual foram escolhidos jovens alunos de violino, e não profissionais de orquestra, se dá ao fato de os mesmos apresentarem DMRP's precocemente, daí a possibilidade deste estudo levantar a importância de um olhar mais atento nesta direção, até porque o estágio inicial do aprendizado do instrumento pode se apresentar como uma oportunidade para professores e alunos observarem cuidadosamente todos os aspectos dos movimentos corporais durante a performance, "incluindo ângulo, tensões, posturas e fazer correções para que os músculos se acostumem a gerar movimentos produtivos e saudáveis" (CRUZEIRO, 2005, p.34). Embora muitos estudos discutam as questões relacionadas com a saúde física de instrumentistas de orquestras, os trabalhos com estudantes somente agora começaram a ser publicados (BOWIE et al., 2000; LLOBET et al., 2000; SPAHN et al., 2004; MILLER et al., 2002). 


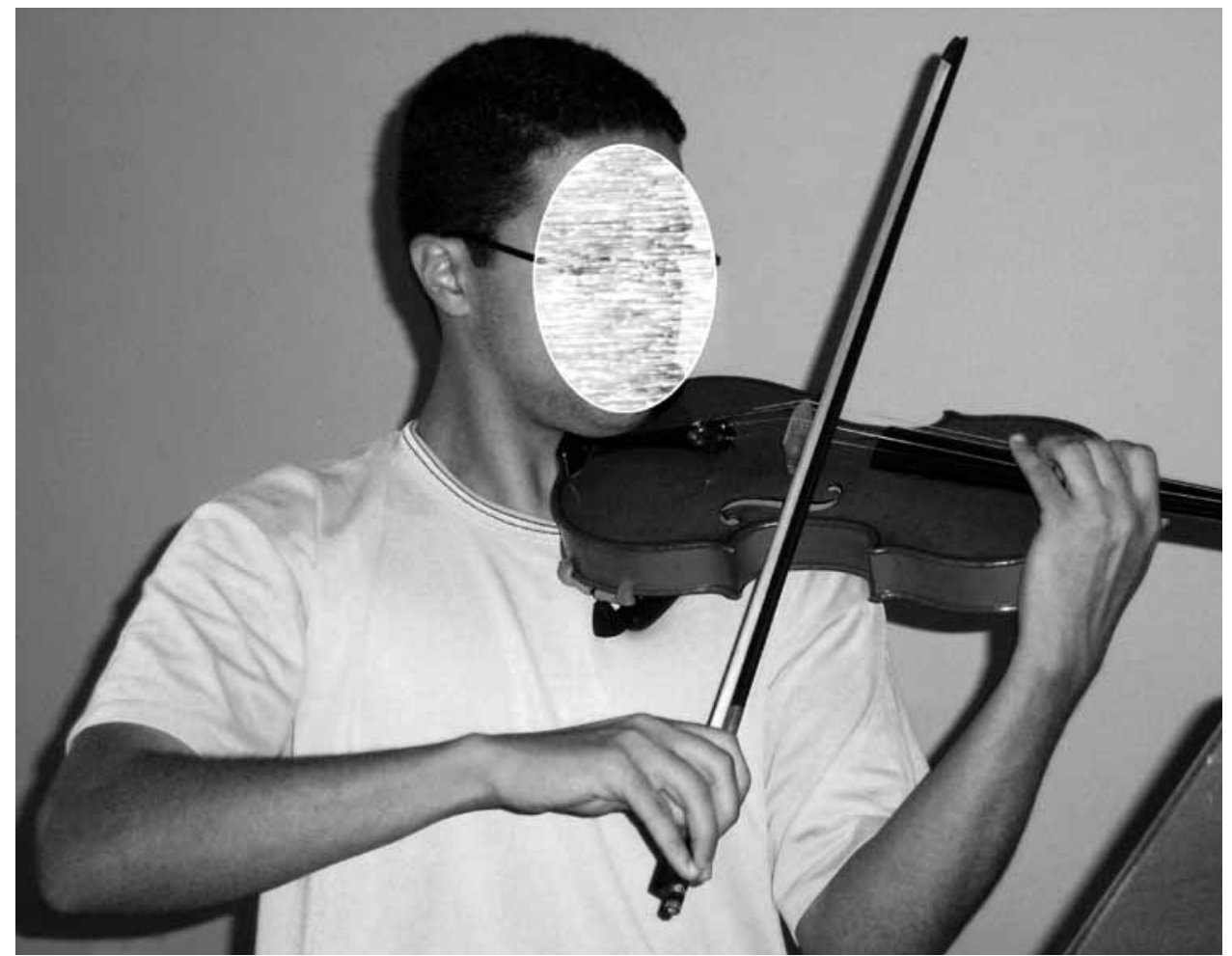

Ex. 1 - Linha média - posições diferentes do corpo nos dois lados

Fonte: Acervo da pesquisadora

De fato, a partir do atendimento clínico, temos observado que, além das questões do uso do corpo na performance, estes estudantes ficam muito tempo por semana estudando para as aulas ou preparando peças para concertos. A questão do tempo dedicado ao instrumento tem sido considerada como sendo um dos fatores de enorme prejuizo à saúde do instrumentista. SCHUELE e LEDERMAN (2004, p.123-128), em estudo realizado sobre desordens ocupacionais em músicos, confirmam que "a maioria dos pacientes indicaram claramente que há uma relação entre o tempo de performance e a dor, sendo que, quando o tempo aumenta, a dor também aumenta".

Este estudo pretendeu ainda iniciar uma reflexão a partir de perguntas tais como: (1) Por que os jovens violinistas estão, frequentemente, apresentando problemas físicos?; (2) Será que estes problemas estão relacionados à forma com a qual seus corpos se comportam durante a performance musical?

Partimos, assim, da hipótese de que alguns dos problemas físicos dos estudantes de violino aparecem como consequência do aprendizado do instrumento, ou seja, algumas das queixas físicas relatadas por eles têm relações de causa e efeito com o uso que fazem de seus corpos durante a performance.

Com o intuito de averiguar esta hipótese, o presente estudo tem os seguintes objetivos: (1) Observar os padrões físicos durante performance musical de seis alunos de violino que cursam a graduação na Escola de Música da UFMG; (2) Compreender se os problemas físicos apresentados por estes alunos têm relação à forma com a qual eles atuam no instrumento; (3) Compreender quais são as possiveis relações dos padrões físicos observados com as queixas dos alunos avaliados; (4) Favorecer o desenvolvimento de uma pedagogia que leve em consideração a saúde dos violinistas; (5) Produzir glossários com descrições e ilustrações dos termos técnicos da área de saúde, que serão usados ao longo da dissertação, de forma a familiarizar os músicos com a problemática tratada na pesquisa.

\section{Problemas físicos de violinistas na performance musical}

Nesta parte do artigo trataremos dos problemas físicos de violinistas relacionados à performance. Foram encontradas, aproximadamente, 80 fontes referentes a este assunto entre artigos, livros, teses e dissertações. Grande parte dos artigos foi encontrada na revista Medical Problems of Performing Artists e outra parte nas revistas PerMusi e The Strad.

\subsection{Os problemas físicos de violinistas e seus sintomas}

A situação dos violinistas no que se refere à má utilização do corpo na performance e aos sintomas físicos por eles experimentados, relacionados à atividade musical, tem sido abordada em pesquisas conduzidas por POLNAUER e MARKS (1964), ROLLAND (1974) e ANDRADE (1988), que discutem os aspectos fisiológicos na execução do violino; por CRUZEIRO (2005), que mostra a importância da prevenção de lesões corporais no violinista a partir da prática pedagógica, e por PETRUS (2005), que aborda os aspectos da saúde dos violinistas de orquestra. 
Podemos citar alguns problemas musculoesqueléticos (referentes ao sistema locomotor) e neuromusculares (referentes aos nervos periféricos e aos músculos) relatados por músicos. São eles: dor; dormência ou formigamento; fadiga ou fraqueza muscular; distonia focal - o termo usado para descrever um grupo de doenças caracterizado por espasmos musculares involuntários que produzem movimentos e posturas anormais; problemas nos nervos periféricos (saem da medula nervosa e vão para os membros) entre outros, muitas vezes causados pela "Síndrome de Sobrecarga ou uso excessivo" ${ }^{3}$ ou "Síndrome de Superuso", que ocorre quando o estresse nas estruturas do corpo é maior do que aquela que podem suportar.

Nos últimos anos, no meu consultório de Fisioterapia, músicos instrumentistas apresentaram diagnósticos como epicondilite (dor no cotovelo), ombro congelado (diminuição da amplitude do movimento do ombro), torcicolo, dor nos punhos, desvios da coluna vertebral, formigamento nas pontas dos dedos das mãos, tendinites, dor de cabeça, estalos nas ATM's (Articulações Temporomandibulares) e vários outros problemas relacionados diretamente à performance.

Quanto às dificuldades causadas pela "Síndrome de Sobrecarga", podemos encontrar um grande número de diagnósticos. Nos indivíduos pesquisados por

DAWSON (2001, p. 68), "os músculos do antebraço e da mão apresentaram-se com maior possibilidade de serem lesados do que os grupos musculares mais proximais ${ }^{4}$ 5". 0 autor se refere a problemas como a tenossinovite estenosante, que é uma inflamação da bainha do tendão, como a condição inflamatória mais encontrada em músicos, com a maior parte dos casos envolvendo os trigger-points (pontos gatilho, regiões sensiveis localizadas nos músculos que provocam dor local ou irradiadas) e os outros com ocorrências da Síndrome de De Quervain (DAWSON, 2001, p.68). As inflamações, incluindo sinovites (inflamação das membranas sinoviais que ficam dentro das articulações) e tendinites, compuseram o segundo grupo mais encontrado. Neste mesmo estudo, a distonia focal ou localizada foi pouco encontrada entre os músicos avaliados, comparada com a compressão do nervo radial. A condição de hipermobilidade articular foi um diagnóstico adicional feito em alguns músicos; ela acontece quando a mobilidade articular está aumentada e pode ser causada por frouxidão dos ligamentos que leva às instabilidades das articulações. As sindromes de compressão nervosa foram provavelmente relacionadas à atividade corporal no instrumento (DAWSON, 2001, p.68).

LIMA (2007, p.9), em estudo realizado com violinistas, em Belo Horizonte, afirma que, dentre os músicos de orquestras, os instrumentistas de cordas friccionadas têm maior prevalência de doenças musculoesqueléticas e neuromusculares. As mãos, os punhos e antebraços são apontados como as áreas mais afetadas, seguidas pelos ombros e coluna vertebral nos violinistas, provavelmente relacionados à posição assumida pela cabeça e pescoço ao sustentar o instrumento, e à movimentação constante do ombro direito durante os movimentos de arco. A região do corpo acometida depende da demanda física de cada instrumento. Alguns fatores podem participar do desenvolvimento dos problemas físicos tais como: repertório acima das condições técnicas do instrumentista, troca de instrumentos que pedem adaptações corporais e uso incorreto do corpo durante a performance. (LIMA, 2007, p.18)

\subsection{Principais fatores causadores dos problemas físicos dos violinistas}

Diversos pesquisadores têm indicado os fatores causadores de tensão muscular e de problemas físicos dos violinistas durante a performance do instrumento. OKNER, et al. (1997, p.112) destacam alguns como: o tipo de queixeira adotada, o uso da espaleira, entre outros. As hipóteses defendidas por estes autores são: composições musicais diferentes resultam em diferentes pressões na queixeira; mudanças na queixeira produzem mudanças na pressão e na força sobre a espaleira durante a performance; mudanças na espaleira produzem mudanças na pressão e na força sobre a queixeira durante a performance e mudanças na quantidade de força e pressão devido a mudanças na queixeira e espaleira se relacionam com a medida do pescoço e dos ombros, e também com a composição musical.

OKNER, et al. (1997, p.112) acreditam que, na maioria das vezes, o uso da espaleira oferece um melhor encaixe entre o corpo dos músicos e o violino. Concordamos em parte com esta ideia, pois na experiência clínica, observamos que alguns violinistas tendem a elevar o ombro contra a espaleira (Ex.2) o que provoca tensão isométrica (de sustentação) na região da cintura escapular (constituída pelas clavículas e pelas escápulas) à esquerda, causando diminuição da oxigenação dos tecidos e levando a posteriores processos fibróticos cicatriciais, ou, nódulos fasciais (relativo às fáscias*) e musculares. Com relação ao uso da espaleira, a altura desta deve estar relacionada com o tamanho do pescoço do violinista.

A sustentação do violino pode também ser causa dos problemas físicos apresentados pelos instrumentistas. OKNER et al. (1997, p.112) esclarecem que a sustentação do violino e a movimentação contínua dos braços acarretam um esforço a mais para o instrumentista. DAWSON observou que sustentar e tocar o violino provoca problemas nas regiões do pescoço e dos ombros. Ele esclarece:

Nervos podem ser pinçados em qualquer nível desde o pescoço ao punho e isto pode causar problemas tais como a Sindrome do Túnel do Carpo. ${ }^{6}$ (Ex.3) [...] Músicos com condições relacionadas a sobrecarga de uso da mão e dos MMSS ${ }^{7}$ continuam a aparecer nos consultórios dos profissionais, em cujo grupo de clientes estão incluídos músicos da performance. Estatísticas mostram que o típico paciente pode ser uma pianista ou um instrumentista de corda, normalmente na segunda ou terceira década da vida, a quem foi dado diagnóstico de lesão no antebraço ou nos músculos das mãos como resultado de sua atividade musical. (DAWSON, 2002, p.2) 


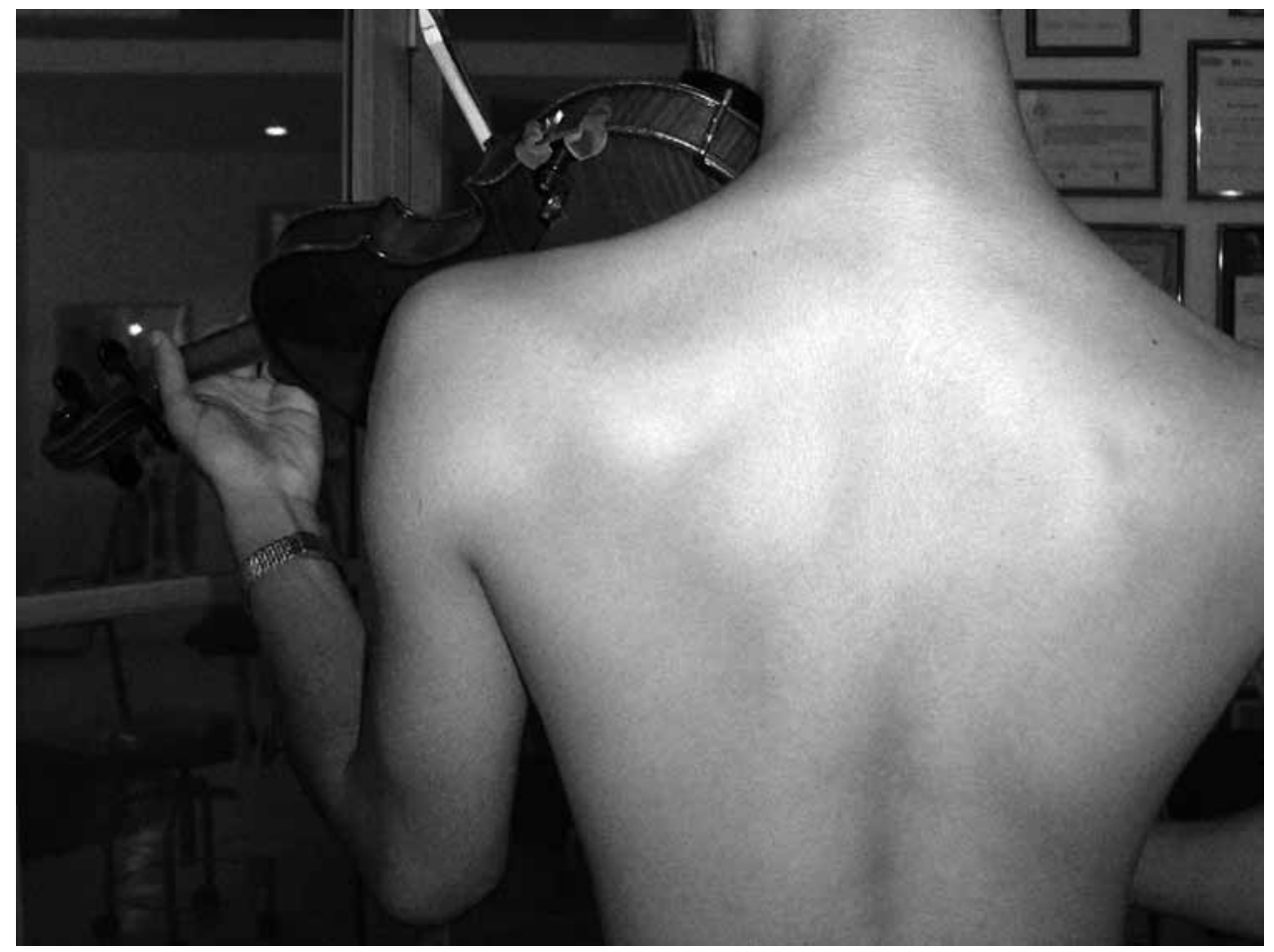

Ex.2 - Elevação de ombro esquerdo contra a espaleira Fonte: Acervo da pesquisadora

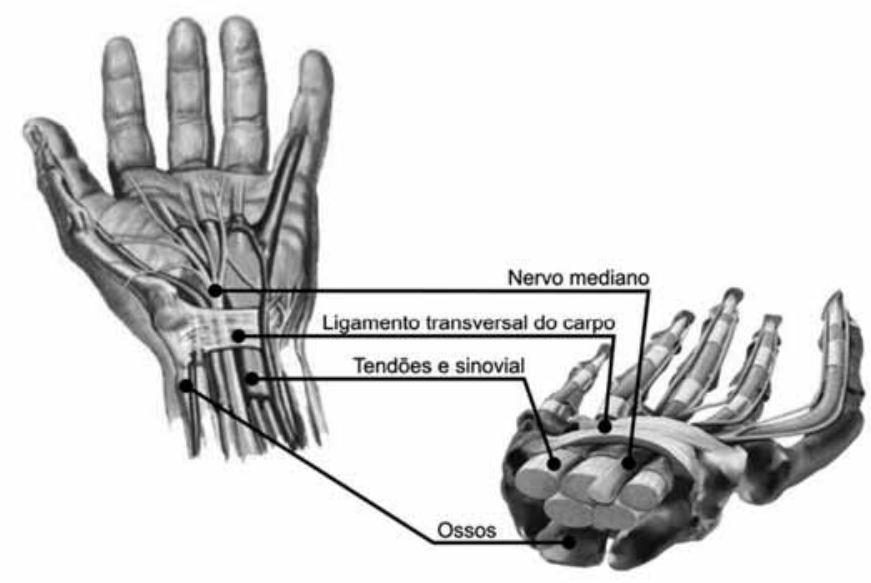

Ex.3 - Túnel do Carpo

Fonte: http://i8.photobucket.com/albums/a40/designiade/tuneldocarpo.jpg

A estrutura do instrumento é outro fator causador de problemas para os instrumentistas de corda. DAWSON (2002, p.139) afirma que características ergonômicas dos instrumentos e suas exigências biomecânicas ${ }^{8}$ especificas parecem determinar um papel quanto à etiologia, ou seja, a causa, localização anatômica e natureza dos problemas de membros superiores (MMSS), braços em músicos. ANDRADE e FONSECA $(2000$, p.1) afirmam que a estrutura do violino e da viola, "favorecem a ocorrência de tensão excessiva durante o tocar por não serem apoiados no chão e pela assimetria dos membros superiores durante a execução." (Ex.4).
0 tipo de técnica usada pelo instrumentista, as solicitações técnicas exigidas para se tocar determinadas passagens, bem como o estudo excessivo do instrumento podem ser também fatores causadores dos problemas físicos apresentados por violinistas. MOURA, FONTES e FUKUJIMA (In COSTA e ABRAHÃO, 2004, p.3) afirmam que, na experiência dos violistas (idem para os violinistas), há movimentos e solicitações técnicas que agravam a sintomatologia tais como execução de notas lentas sustentadas e o vibrato, entre outras. De acordo com SZENDE (1971), no livro The Physiology of Violin Playing, o 


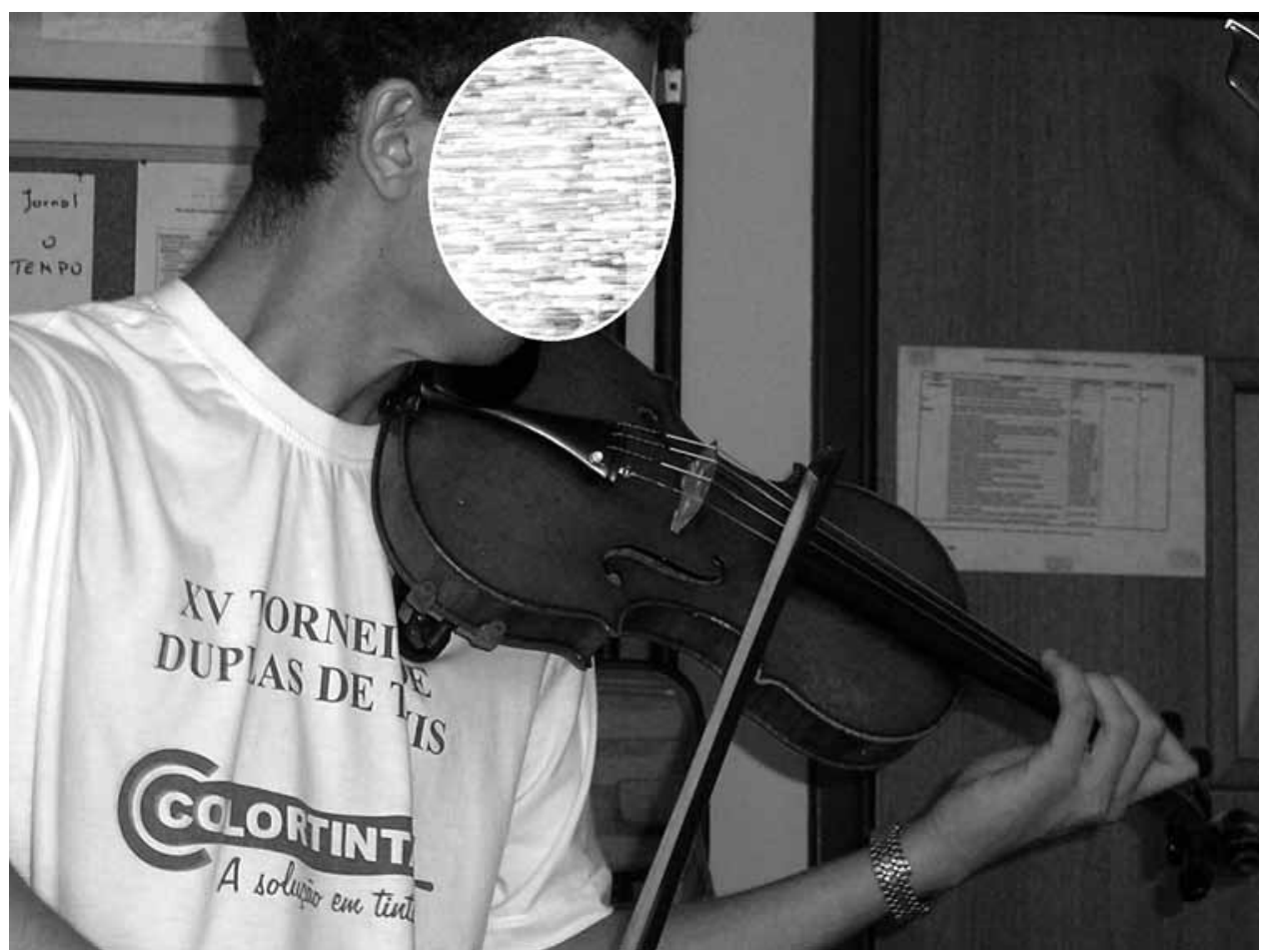

Ex.4 - Tensão e assimetria durante performance

Fonte - Acervo da pesquisadora

vibrato é "uma função muscular intermitente que envolve todos os músculos do braço". Durante a execução do vibrato, a pressão da cabeça para sustentar o instrumento aumenta a fim de possibilitar maior liberdade de ação para o braço esquerdo, causando uma maior tensão nos músculos do pescoço. Na maioria das vezes, para sustentar o movimento repetitivo de pequena amplitude que caracteriza o vibrato, o violinista acaba por realizar uma co-contração, ou seja, uma contração simultânea dos músculos agonistas, que são os músculos responsáveis por um movimento e antagonistas, os responsáveis pelo movimento oposto ao do agonista. Já na execução de notas lentas e sustentadas, é necessária uma boa estabilização das articulações do corpo envolvidas nesta ação através da manutenção de uma ação muscular bem controlada, que é mantida por mais tempo em contração isométrica, ou seja, de sustentação.

DAWSON (2002, p.139), acredita que a maioria das lesões físicas em músicos ocorre devido aos movimentos repetitivos, realizados com muito esforço, o que resulta processos patológicos específicos. Conforme POLISI (2005, p.113-116), muitas vezes o violinista vê a perfeição técnica como o alvo a ser alcançado em sua performance. A busca excessiva de uma técnica perfeita tem levado ao fim muitas carreiras musicais. Além disso, o excesso de estudo do instrumento tem causado lesões físicas porque o músico, principalmente o aluno, está mais envolvido conscientemente com o resultado sonoro a ser alcançado do que com suas condições físicas para a prática do instrumento (POLISI, 2005, p.113-116).

Em nossa experiência na clínica fisioterápica, confirmamos estes achados e acrescentamos ainda questões relacionadas com a ergonomia, com o aspecto psicológico, com o excesso de atividades musicais extra-universidade e com o tempo de estudo. Importante também ressaltar o grande número de pacientes músicos que nos chegam com lesões físicas devido à prática de atividade física mal orientada. Muitas vezes, a falta de informação sobre 0 funcionamento do corpo faz com que alguns nos relatem dores nas mãos após ficarem apertando bolinha de tênis por longo período de tempo, por exemplo. Ora, se os violinistas e outros instrumentistas já utilizam a flexão dos dedos repetidamente no ato de tocar seus instrumentos, apertar a bolinha, cujo movimento é similar - flexão de dedos e ainda com esforço -, isso só poderá levar à fadiga os músculos responsáveis por este movimento. Outra realidade importante que devemos levar em consideração como fator nocivo ao corpo do músico é a falta de alongamento e aquecimento realizado regularmente e principalmente nos períodos que precedem as performances.

Acreditamos que, na maioria das vezes, o que leva ao aparecimento das DMRP's, se trata de um conjunto de fatores combinados e não apenas uma causa isolada. 


\section{Avaliação física do violinista}

Resolvemos acrescentar uma seção específica para tratar de uma questão fundamental na compreensão das DMRP's: a avaliação física do violinista. Através da avaliação do violinista em performance e também sem o instrumento (como realizo na prática em consultório), podemos compreender, de forma mais clara, os padrões de gestos e posturas utilizados por eles, além de fazer as análises cinesiológica e biomecânica tão necessárias à compreensão do uso de seus corpos durante a atividade musical (ACKEMANN e ADAMS, 2004).

Essencial que as avaliações (tanto aquela realizada sem 0 instrumento, quanto a realizada durante a performance musical) ocorram antes do tratamento, para que 0 terapeuta possa identificar quais as possiveis fontes dos problemas apresentados pelo paciente. $\mathrm{Na}$ anamnese (questionário), questões específicas relacionadas com a vida do músico devem ser exploradas como: (1) Há quanto tempo toca o instrumento; (2) Quanto tempo de performance por dia; (3) Como e quanto carrega o seu instrumento em direção aos locais onde realizará as performances; (4) Quanto tempo de intervalo durante o período de estudo, ou gravação; entre várias outras.

Em estudo realizado por BRANDFONBRENER e BURKHOLDER (2004, p.116-122), encontramos confirmação da importância da relação entre a observação da performance e a prevenção de problemas físicos. As autoras dizem ser crucial a realização de uma avaliação cuidadosa no jovem músico com lesão física, com e sem o instrumento, do que pode depender seu futuro profissional.

\section{Padrões físicos e queixas a partir da avaliação dos seis alunos de violino}

Nesta seção, ao apontarmos os padrões físicos inadequados dos seis alunos de violino, a partir do olhar da Fisioterapia e das áreas de atuação de cada componente do Painel de Avaliadores ${ }^{9}$, não pretendemos afirmar que os seis violinistas se comportam tecnicamente de forma inadequada, ou que os padrões por eles apresentados levarão, necessariamente, às DMRP's. Nosso objetivo é enfatizar a importância de se conhecer as posturas e os gestos utilizados por estes instrumentistas e a necessidade de consciência corporal durante a performance, para que possamos refletir sobre o tema e favorecer a prevenção de possiveis problemas físicos, possiveis de ocorrer em estudantes de violino.

Pelo fato de que foi encontrado um número muito grande de padrões corporais inadequados durante os momentos de performance dos alunos, decidimos por apontar somente os mais importantes. Foram utilizados dois critérios para a escolha destes padrões: (1) A frequência de sua ocorrência e; (2) A gravidade dos mesmos.

Quanto à forma de condução das observações, concordamos com o conceito apresentado nesta dissertação por diversos autores da Fisioterapia, que afirma que o corpo humano é uma unidade inteira e interconectada. Porém, para facilitar o entendimento das discussões aqui apresentadas, escolhemos analisar o comportamento físico dos seis alunos de violino a partir da divisão em regiões corporais. Essa divisão foi definida a partir dos dados recolhidos pela observação dos alunos de violino em performance nas quatro situações de aprendizado do instrumento e na avaliação fisioterápica.

OBS: No Ex.5 não estão presentes todas as queixas, mas somente aquelas que têm relações cinesiológicas e biomecânicas com os padrões físicos observados tanto pela pesquisadora quanto pelo PA.

A partir dos dados do Ex.5, podemos identificar algumas relações bastante óbvias e diretas entre padrões e queixas como, por exemplo: os padrões Tensão de ECM e musculatura lateral do pescoço à direita (3.2), Tensão de nuca (3.3) e Grande tensão cervical (3.4) e as queixas Torcicolo(F) e Tensão e dor na nuca (E); os padrões Elevação de ombro à direita (4.1), Elevação de ombro à esquerda (4.2) e a queixa Tensão, dor e cansaço nos trapézios (I); o padrão Tensão no polegar D (6.11) e a queixa Dor no polegar direito (M); o padrão Hiperlordose da coluna lombar (12.1) e a queixa Lombalgia (T).

Entendemos que, de tanto os alunos repetirem estes padrões inadequados, com o passar do tempo, através das compensações, o corpo vai reagindo e apresentando alguns sintomas que podem incomodar o instrumentista de imediato, ou mais tarde, no caso dos indivíduos que apresentam menor consciência corporal. Estes padrões podem acarretar agravamentos do estado patológico das estruturas corporais envolvidas.

Em nossa experiência clínica observamos que, devido ao grande envolvimento com a produção mecânica e sonora durante a execução de uma peça, o músico na maioria das vezes coloca sua percepção corporal abaixo de seus interesses musicais. Por isso, em doze anos de experiência da pesquisadora no atendimento fisioterápico a músicos, o número de pacientes que apresentam um processo inicial de instalação de DMRP's é mínimo, quando comparado ao dos que nos procuram já com sua performance bastante prejudicada.

Como especificado anteriormente, os padrões físicos inadequados mais encontrados nos seis alunos de violino foram observados antes de obtermos deles 0 relato de suas queixas físicas, colhidas na avaliação fisioterápica. A coincidência entre os relatos dos alunos e as observações (da pesquisadora e do PA) valida as possíveis relações de causa e efeito entre os dois elementos. Por outro lado, a coincidência dos padrões observados pela pesquisadora e pelo PA confirmam a existência de tais padrões e suas influências sobre a performance dos alunos. 


\begin{tabular}{|c|c|c|}
\hline & PADRÕES & QUEIXAS \\
\hline 1 - FACE & $\begin{array}{l}1.1 \text { - Tensão de boca e ATM } \\
1.2 \text { - Mandibula desviada à D } \\
1.3 \text { - Mandibula desviada à E } \\
1.4 \text { - Oposição da mandíbula em relação ao violino }\end{array}$ & $\begin{array}{l}\text { A - Bruxismo } \\
\text { B - ATM's estalam }\end{array}$ \\
\hline 2 - CABEÇA & $\begin{array}{l}2.1 \text { - Protusão } \\
2.2 \text { - Rotação à E e inclinação à D } \\
2.3 \text { - Tensão excessiva na sustentação do violino }\end{array}$ & C - Dor de cabeça \\
\hline 3 - PESCOÇO & $\begin{array}{l}3.1 \text { - Retificação } \\
3.2 \text { - Tensão de ECM e musculatura lateral do pescoço à D } \\
\text { 3.3 - Tensão de nuca } \\
3.4 \text { - Grande tensão cervical }\end{array}$ & $\begin{array}{l}\text { D - Pescoço endurece e estala } \\
\text { E - Tensão e dor na nuca } \\
\text { F - Torcicolo }\end{array}$ \\
\hline 4 - OMBRO & $\begin{array}{l}4.1 \text { - Elevação à D } \\
4.2 \text { - Elevação à E } \\
4.3 \text { - Flexão com abdução excessiva à D } \\
4.4 \text { - Protusão bilateral }\end{array}$ & $\begin{array}{l}\text { G - Dor nos trapézios, principalmente à E } \\
\text { H - Dor e cansaço no ombro E } \\
\text { I - Tensão, dor e cansaço nos trapézios }\end{array}$ \\
\hline 5 - ESCÁPULA & $\begin{array}{l}\text { 5.1 - Má utilização do ritmo escapuloumeral com uso excessivo } \\
\text { de movimentos da escápula e menor e inadequada } \\
\text { utilização da articulação gleno-umeral à D } \\
5.2 \text { - Escápula alada }\end{array}$ & $\mathrm{J}$ - Ombros estalam a qualquer movimento \\
\hline 6 - DEDO & $\begin{array}{ll}6.1 \text { - } & \text { Hiperextensão da falange média do dedo mínimo da } \\
& \text { mão E com flexão de noventa graus da falange distal } \\
6.2 \text { - } & \text { Extensão de indicador E } \\
6.3 \text { - } & \text { Extensão de dedo mínimo à D } \\
6.4 \text { - } & \text { Extensão dos dedos que não estão nas cordas à E } \\
6.5 \text { - } & \text { Hiperextensão do metacarpo e tensão no polegar } \\
& \text { esquerdo } \\
6.6 \text { - } & \text { Hiperextensão e tensão de dedos do lado E, durante } \\
& \text { harmônicos } \\
6.7 \text { - } & \text { Tensão no indicador da mão D } \\
6.8 \text { - } & \text { Flexão com tensão dos dedos da mão E quando estão } \\
& \text { fora de contato com as cordas } \\
6.9 \text { - } \quad \begin{array}{l}\text { Tensão forte do polegar no braço do instrumento na } \\
\text { parte posterior }\end{array} \\
6.10 \text { - Muita pressão dos dedos da mão E nas cordas } \\
6.11 \text { - } \quad \text { Tensão no polegar D } \\
6.12 \text { - Distribuição de tensão irregular nos dedos da mão D } \\
\text { ao segurar o arco (dedo mínimo com hiperextensão } \\
\text { de falanges médias e distais) com flexão da falange } \\
\text { proximal e extensão das outras falanges do } 5^{\circ} \text { dedo }\end{array}$ & $\begin{array}{l}K \text { - Dor no braço } E \\
L \text { - Polegar } D \text { em gatilho } \\
M \text { - Dor no polegar } D\end{array}$ \\
\hline 7 - MÃO & $\begin{array}{l}7.1 \text {-Tensão de mão e dedos à } E \\
7.2 \text { - Extensão com tensão de metacarpos da mão D } \\
7.3 \text { - Grande tensão muscular nas mãos }\end{array}$ & $\begin{array}{l}\mathrm{N} \text { - Dor na mão } \mathrm{E} \\
\mathrm{O} \text { - Dor nas mãos }\end{array}$ \\
\hline 8 - PUNHO & $\begin{array}{l}8.1 \text { - Flexão com tensão à E } \\
8.2 \text { - Flexão à D } \\
8.3 \text { - Punho D em extensão acima da posição funcional }\end{array}$ & \\
\hline 9 - ANTEBRAÇO & $\begin{array}{l}9.1 \text { - Pronação à D } \\
9.2 \text { - Supinação à E }\end{array}$ & $P$ - Dor e endurecimento no antebraço $E$ \\
\hline 10 - GERAL & $\begin{array}{l}\text { 10.1 - Tensão no braço D } \\
\text { 10.2 - Braço D muito elevado }\end{array}$ & Q - Dor no braço D \\
\hline
\end{tabular}




\begin{tabular}{|c|c|c|}
\hline $\begin{array}{l}11 \text { - COLUNA } \\
\text { TORÁCICA }\end{array}$ & 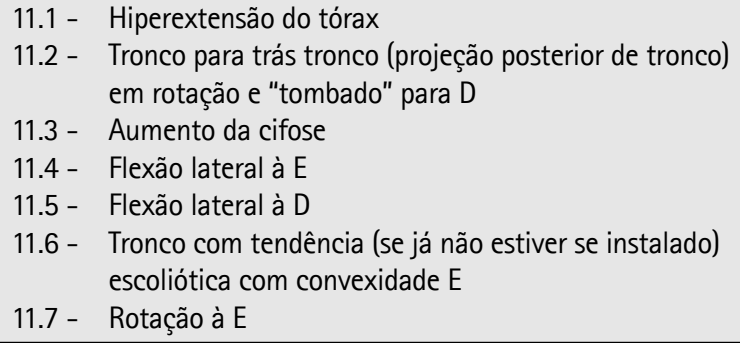 & $\begin{array}{l}\mathrm{R} \text { - Dor na coluna torácica } \\
\mathrm{S} \text { - Dor no peito }\end{array}$ \\
\hline $\begin{array}{l}12 \text { - COLUNA } \\
\text { LOMBAR }\end{array}$ & $\begin{array}{l}\text { 12.1 - Hiperlordose } \\
12.2 \text { - Protusão abdominal }\end{array}$ & T - Lombalgia \\
\hline 13 - QUADRIL & $\begin{array}{l}13.1 \text { - Rotação interna bilateral } \\
13.2 \text { - Rotação externa bilateral } \\
\text { 13.3 - Desviado à D }\end{array}$ & $\begin{array}{l}U \text { - Pernas ficam duras quando toca sob } \\
\text { tensão } \\
V \text { - Dor nas pernas }\end{array}$ \\
\hline \multirow{3}{*}{$\begin{array}{l}14-\text { JOELHO } \\
15-\text { PÉ } \\
16 \text { - GERAL }\end{array}$} & 14.1 - Hiperextensão & $X$ - Dor no joelho D \\
\hline & 15.1 - Pronação bilateral & \\
\hline & 16.1 - Transferência de peso à E & \\
\hline
\end{tabular}

Ex.5 - Relação entre os padrões inadequados observados pela pesquisadora e pelo PA e as queixas dos seis alunos de violino

\section{Conclusão}

Este estudo procurou observar e avaliar os padrões físicos inadequados apresentados por seis alunos de violino do curso de Graduação da Escola de Música da UFMG, durante a prática de seu instrumento.

A partir de revisão de literatura de pesquisas médicas que tratam do adoecimento de músicos, juntamente com aqueles relacionados à Fisioterapia, pudemos então perceber a busca de respostas para as perguntas relacionadas na introdução e que poderia iluminar a pedagogia do violino no que se refere aos aspectos corporais, ajudando no desenvolvimento de um pensamento mais unificado entre pedagogia do instrumento e saúde do músico.

Por isso, efetivamos um estudo especializado do comportamento corporal dos seis alunos de violino em quatro situações de performance diferentes: (1) Aula de violino individual; (2) Aula de violino coletiva; (3) Seção de estudo do violino e (4) Performance pública, além da Avaliação Fisioterápica completa (anamnese e avaliação postural e gestual, com e sem o violino). Os alunos foram observados pela pesquisadora e foram fotografados e filmados; as fotos e filmes foram enviados para um Painel de Avaliadores para que pudessem confirmar ou acrescentar a visão da pesquisadora.

A revisão de literatura deste estudo apresentou evidências de que a preocupação com a situação da saúde física do violinista é relevante. Isto se deve, provavelmente, ao número de violinistas que têm suas carreiras prejudicadas ou até mesmo paralisadas por conta de DMRP's. Portanto, os profissionais da área da saúde bem como os professores, estudantes e praticantes de violino, necessitam urgentemente voltar seus olhares para esta realidade: tocar violino requer um esforço físico acentuado (FONSECA, 2007, p.2; FRANK e MUHEN, 2006, p.1) e por isso, torna-se indispensável a realização de estudos especializados sobre as relações anatômicas, biomecânicas e cinesiológicas do músico com sua atividade musical.

Conforme LIMA (2007, p. 66), durante a performance musical os músicos não percebem as adequações posturais ou compensações que necessitam realizar, aumentando a sobrecarga de trabalho corporal, podendo, assim, contribuir para a manutenção ou surgimento de sintomas, como dor ou fadiga muscular, entre outros.

A coleta de dados desta pesquisa confirmou o encontrado na revisão bibliográfica: os seis alunos de violino observados apresentaram padrões físicos inadequados que poderiam, eventualmente, prejudicar suas performances e sua saúde. Entre as queixas apresentadas pelos alunos durante a avaliação fisioterápica, pudemos encontrar estalos nas ATM's, torcicolos, dores nos braços, tensão nos trapézios, dores de cabeça. E alguns dos padrões físicos que os seis alunos apresentaram foram: a tensão na mão esquerda, a flexão de tronco à esquerda, a transferência de peso para a perna esquerda, dor no polegar direito, dificuldades respiratórias, entre tantas outras.

Os resultados da análise dos dados coletados pela pesquisa apontaram para quatro fatos importantes: (1) Houve uma coincidência nos padrões observados pela pesquisadora e pelo PA; (2) Houve identificação, pela visão da Fisioterapia, entre os padrões físicos inadequados recorrentes nos seis 
alunos de violino e as queixas apresentadas pelos mesmos durante uma das etapas de observação - a avaliação fisioterápica; (3) Os seis alunos de violino observados não tinham consciência da maioria de seus padrões físicos inadequados durante a performance e se referiram a um total desconhecimento de aspectos relacionados com o conhecimento do funcionamento do próprio corpo durante a performance e (4) Os seis alunos observados parecem estar mais preocupados com a quantidade de performances por mês do que com a qualidade de seus movimentos durante cada uma.

Acreditamos que, com estudos como este, poderemos despertar a atenção dos alunos e professores de violino para a importância da consciência corporal durante a performance do instrumento; esperamos que os violinistas alcancem uma maior simetria e maior relaxamento das regiões corporais envolvidas no ato de tocar. A possibilidade de adoecimento relacionada à performance do violino poderá, assim, ser prevenida e reduzida.

Não se tem notícia de que existam escolas de música no Brasil que incluam, em seu currículo básico da graduação, disciplinas relacionadas com o conhecimento de Anatomia e Fisiologia Humana e suas implicações para a prática com o instrumento. Adicionalmente, não há uma consciência por parte da maioria dos músicos quanto à importância de se consultar profissionais da área da saúde quando surgem sintomas de problemas físicos devido ao estudo e performance com 0 instrumento (ROSET-LLOBET, et al., 2000, p.167-174). E, normalmente, um primeiro pensamento que passa por suas mentes no início de algum incômodo é que aquilo vai passar sozinho, sem tratamento.

Esperamos que, a partir das discussões empreendidas neste presente estudo, possamos compreender melhor 0 mecanismo dos padrões inadequados e das possiveis lesões ocorridas em alunos de violino e em violinistas, e mesmo em outros músicos. Assim, talvez possamos oferecer recursos para que a área de saúde e para que as pedagogias dos instrumentos possam lidar melhor com estes problemas. Se os estudantes de violinos e se estudantes de música em geral se voltarem para esta realidade, estaremos contribuindo para que o cuidado com a saúde os atinja durante o processo de aprendizado, fazendo com que suas vidas como profissionais sejam mais bem conduzidas em se tratando do aspecto físico da performance.

\section{Referências}

ACKERMANN, B., ADAMS, R. Interobserver reliability of general practice physiotherapists in rating aspects of the movement patterns of skilled violinists, Medical Problems of Performing Artists, 19, n. 1, p.3, 2004.

ANDRADE, E. O. A comprehensive performance project in violin literature with na essay entitled: body awareness in physical and psychological aspects of violin playing. lowa: University of lowa, 1988.

ANDRADE, E. Q.; FONSECA, J. G. M. Artista- atleta: reflexões sobre a utilização do corpo na performance dos instrumentos de corda. Per Musi, Belo Horizonte, 2:118-128, 2000.

BOWIE E., BRIMER K. et al. Nerve Conduction Studies in Young Adult Violinists. Medical Problems of Performing Artists, $15, n ; 3, p .123,2000$.

BRODSKY, M.; HUI, K. An Innovative Patient-centered Approach to Common Playing-related Pain Conditions in Musicians. Medical Problems of Performing Artists, 19:170-173, 2004.

CARRINGTON, W.; CAREY, S. Explaining the Alexander Technique:The Writings of F. Matthias Alexander, Sheildrake Press, 1992.

COSTA, C.; ABRAHÃO J. Quando o tocar dói: um olhar ergonômico sobre o fazer musical. Per Musi. Belo Horizonte: Escola de Música da UFMG, n. 10, p.60-79, 2004.

CRUZEIRO, R. 0 movimento corporal na prática pedagógica do violino: um estudo com professores de adolescentes iniciantes. Porto Alegre: Universidade do Rio Grande do Sul - Instituto de Artes, 2005.

DAWSON, W. J. Playing with Pain - Help for Muscular and Skeletal Problems in the Double Reed Musician, Arts-Medicine Clinics, Illinois: United States Facilities, Jan, 1998.

Upper Extremity Overuse in Instrumentalists, Medical Problems of Performing Artists, 16, 16-66, 2001.

Upper-extremity Problems Caused by Playing Specific Instruments, Medical Problems of Performing Artists, 17:135-140, 2002.

FONSECA, J. G, Frequência dos problemas neuromusculares ocupacionais de pianistas e sua relação com a técnica pianística - uma leitura transdisciplinar da medicina do músico. Tese de Doutorado. Escola de Medicina da UFMG, 2007.

FONSECA, M.P.M. Os principais desconfortos físico-posturais dos flautistas e suas implicações no estudo e na performance da flauta. Dissertação de Mestrado. Escola de Música da UFMG, 2005. 
FRANK, A.; MUHLEN, C. A. Queixas musculoesqueléticas em músicos: prevalência e fatores de risco, Revista Brasileira de Reumatologia, Alemanha, Playing-related musculoskeletal complaints among musicians: prevalence and risk factors, 2006.

GREEF, M.; WIJCK; REYNDERS, K.; TOUSSAINT, J.; HESSELING, R. Impact of the Groningen Exercise Therapy for Symphony Orchestra Musicians Program on Perceived Physical Competence and Playing-Related Musculoskeletal Disorders of Professional Musicians, Medical Problems of Performing Artists, 18:156-160, 2003.

KANEKO, Y.; LIANZA, S.; DAWSON W. J., Pain as an Incapacitating Factor in Symphony Orchestra Musicians in São Paolo, Brazil, Medical Problems of Performing Artists,v. 20, n.4, p. 168-174, 2005.

LAGE, G.; BORÉM F. et al. Aprendizagem motora na performance musical: reflexões sobre conceito e aplicabilidade. Per Musi. Belo Horizonte: Escola de Música da UFMG, 5/6:14-37, 2002.

LIMA, R.C. Distúrbios Funcionais Neuromusculares Relacionados ao Trabalho: Caracterização Clínico-Ocupacional e Percepção De Risco Por Violinistas de Orquestra, Saúde Pública, Faculdade de Medicina da UFMG, Belo Horizonte, 2007.

LLOBET, J, R. Problemas de Salud de los músicos y su relación con la educación. XXVI Conferencia de la International Society for Musical Education y Seminario de la CEPROM. Barcelona e Tenerife, 2004.

MCCULLOUGH,C.P. The Alexander Technique and the String Pedagogy of Paul Rolland,1996.

Disponivel na Internet: http://www.alexandercenter.com/pa/ stringsiii.html \#dstring

MILANESE S., Physiotherapy Services during the Performance of Wagner's Ring Cycle by the Adelaide Symphony Orchestra: A Model of Early Intervention for Playing-related Musculoskeletal Disorders, Medical Problems of Performing Artists,v.15, n.3, p.107-110, 2000.

MILLER G., PECKF. and WATSON J. S., Pain Disorders and Variations in Upper Limb Morphology in Music Students, Medical Problems of Performing Artists, 17:169-172, 2002.

MOURA, R. C. R.; FONTES, S.V. \&t FUKUJIMA, M.M. Doenças Ocupacionais em Músicos: uma Abordagem Fisioterapêutica, Rev. Neurociências, n.8, v.3, p.103-107, 2000.

OKNER M.; KERNOZEK T. WADE M. Chin Rest Pressure in Violin Players: Musical Repertoire, Chin Rests, and Shoulder Pads as Possible Mediators, Medical Problems of Performing Artists,12, n.4, p.112, 1997.

PEDERIVA, P. 0 corpo no processo ensino-aprendizagem de instrumentos

musicais: percepção de professores. Dissertação de mestrado. Universidade

Católica de Brasília, 2005.

Significados de Corpo na Performance Musical: o corpo como veículo de expressão da sensibilidade. In CONGRESSO ANUAL DA ANPPOM, XVI, 2006, Brasília. Anais. Brasilia: ANPPOM, 2006a.

Soluções para problemas corporais no ensino-aprendizagem da performance musical: percepções de professores de instrumento. In

ENCONTRO ANUAL DA ASSOCIAÇÃo BRASILEIRA DE EDUCAÇÃo MUSICAL, 14, 2006, João Pessoa. Anais. João Pessoa: ABEM, 2006b.

PEDERIVA, P.; GALVÃo, A. Significados de Corpo na Performance Musical: o corpo como veículo de expressão da sensibilidade. Anais do XVI Congresso da ANPPOM, Brasília, p.634-637, 2006.

PETRUS, A. Produção Musical e o Desgaste músculo-esquelético: principais condicionantes da carga de trabalho dos violinistas de uma orquestra. Belo Horizonte: Escola de Engenharia - Departamento de Engenharia de Produção da UFMG, 2005.

POLISI J. W. The subtle art: educating the musician of the twenty-first century (anniversary article), Medical Problems of Performing Artists, v.20, n.1, p.52, 2005.

POLNAUER, DR. FREDERICK F. Senso-Motor Study and Its Application to Violin Playing, American String Teachers Association, Urbana, 1964.

RICHERME, C. A técnica Pianística - uma abordagem científica. Editora Air, São

João da Boa Vista (SP), p. 294, 1996.

ROSET-LLOBET, J.; ROSINÉS-CUBELLS, D.; SALÓ-ORFILA J. Identification of Risk Factors for Musicians in Catalonia (Spain), Medical Problems of Performing Artists, 15:167-174, 2000.

SANTIAGO, P. F. The application of Alexander Technique principles to piano teaching for beginners. 2000. $88 \mathrm{f}$. Dissertation (Masters of arts in music education) - Institute of Education, University of London. London, 2000.

An exploration of the potential contributions of the Alexander Technique to piano pedagogy. 2004. $423 \mathrm{f}$. Thesis (Doctor of philosophy) - Institute of Education, University of London. London, 2004.

A perspectiva da Técnica Alexander sobre os problemas físicos da performance pianística. In: ANPPOM, 15, Rio de Janeiro, 2005.

Potenciais contribuições da Técnica Alexander para a pedagogia pianística. In: ABEM, 12., Fortaleza, 2006.

SCHUELE S. U., LEDERMAN R. J., Occupational Disorders in Instrumental Musicians, Medical Problems of Performing Artists, 19:123-128, 2004. 
SHAN G.; VISENTIN P. A quantitative three-dimensional analysis of arm kinematics in violin performance, Medical Problems of Performing Artists, v.19, n.1, p. 3, 2003.

SHAN G.; VISENTIN P.; SCHULTZ A. Multidimensional Signal Analysis as a Means of Better Understanding, Medical Problems of Performing Artists, 19:129-139, 2004.

SPAHN, C.; STRUKELY, S.; LEHMANN, A. Health conditions, attitudes toward study, and attitudes toward health at the beginning of university study: music students in comparison with other student populations, Medical Problems of Performing Artists, v.19, n.1, p.26, 2004.

SZENDE, O.; NEMESSURI, M. The Physiology of Violin Playing. London: Collet's, 1971.

VISENTIN, P.; SHAN, G. The kinetic characteristics of the bow arm during violin performance: an examination of internal loads as a function of tempo, Medical Problems of Performing Artists, v.18, n.3, p.91, 2003.

.Innovative Approach to Understand Overuse Injuries: Biomechanical Modeling as a Platform to Integrate Information Obtained from Various Analytic Tools, Medical Problems of Performing Artists, v.19, n.2, p.90, 2004.

ZAZA C. Playing-related musculoskeletal disorders in musicians: a systematic review of incidence and prevalence, Canadian Medical Association Journal, v.158, n. 8, p.1019-1025: Canadian Medical Association, 1998.

\section{Notas}

1 Refere-se aos músculos, ossos, nervos e outras estruturas ligadas à sustentação e movimentação do corpo humano.

2 Originalmente "Overuse Syndrome", se refere a um conjunto de condições caracterizadas pelo desconforto ou pela dor persistente nos músculos, tendões e outros tecidos moles, com ou sem manifestações físicas. (Worksafe Austrália National Code of Practice for the Prevention of Occupational Overuse Syndrome, 1994)

3 Próximos do centro do corpo.

4 Provocada pela compressão do nervo mediano, que vem do braço e passa pelo punho.

5 MMSS - membros superiores, ou braços.

6 Referente à Biomecânica, ciência que estuda as forças físicas que agem sobre os corpos.

7 Medicina, Música, Terapia Ocupacional e Fisioterapia (abordagem de Cadeias Musculares).

Carolina Valverde Alves é fisioterapeuta graduada pela Faculdade de Ciências Médicas de Minas Gerais em 1991. Especializada no Conceito Neuroevolutivo Bobath desde 1992. Formada em técnicas de Terapia Manual como Crochetagem Mioaponeurótica e Mulligan. Atua na clínica especializada e na pesquisa em Saúde do Músico desde 1993. Membro do EXERSER - Núcleo de Atenção Integral à Saúde do Músico desde 1999. Saxofonista amadora desde 2002. Foi professora do Curso de Extensão "Saúde do músico - Reeducação postural e gestual na atividade musical" na Escola de Música da UFMG no ano de 2003. Mestra em Música pela Escola de Música da UFMG em 2008. Professora da Escola de Música da UEMG desde 2009 nos cursos de graduação do Bacharelado e Licenciatura. Colunista do Jornal Musical (Órgão Oficial do Sindicato dos Músicos Profissionais do Estado do Rio de Janeiro) desde 2009. 